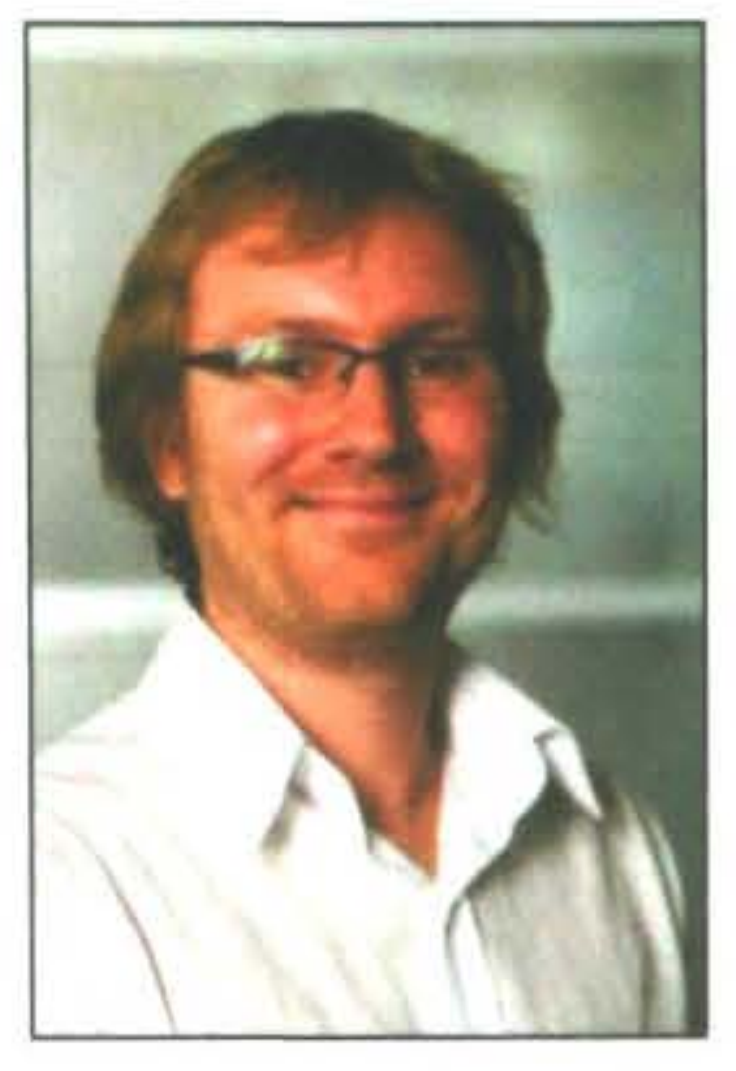

\title{
WHY ARE THERE SO MANY \\ SHORT JOBS IN LEED?
}

\author{
Jason Timmins ${ }^{1}$ \\ Work Directions, \\ Department of Labour
}

\begin{abstract}
The main objective of this paper is to investigate the use of earnings spells in LEED as a measure of job tenure. The paper explores the extent to which employment relationships in LEED contain multiple job (earnings) spells and the impact on the tenure distribution if individual job spells, between an employer and employee, are joined together. The study found that one in five jobs (21.1 percent) in LEED, as at March 2006, were repeat spells with the same employer and nearly half (44.4 percent) of repeat-job spells started following a single month of non-employment and only 16.2 percent of repeat spells occurred after a non-employment period of over 12 months. Imputing all nonemployment periods as employment had a measurable, but not a particularly dramatic effect on the job tenure distribution. For example, the share of job spells with elapsed tenure of 12 months or less falls by only 10 percentage points from 48.1 percent to 38.0 percent, a decline of around 20 percent. A distinctive pattern among repeat-job spells was for an earnings spell to end in December and for a new spell to begin in February. Around a quarter of all repeat spells, separated by a single month, start in February, in particular, 63.1 percent of job spells in the education industry fall into this category.
\end{abstract}

\section{Introduction}

In New Zealand, firms in the horticulture and viticulture industries are finding it increasingly difficult to recruit a sufficient number of local workers, especially during the peak picking season, and are being forced to look offshore. The ongoing shortage of seasonal workers prompted the New Zealand Government to introduce the Recognised Seasonal Employment (RSE) programme. The aim of RSE is to help the horticulture and viticulture industries recruit workers from Pacific States.

The RSE programme, together with other Government initiatives designed to improve the supply of seasonal workers, have increased the need for information about seasonal workers, firms and industries in New Zealand to support policy decision making. The monthly reporting of earnings of all employees within New Zealand makes LEED ideal for summarising short employment spells that are associated with seasonal jobs. However, a potential weakness of LEED is that the start and end dates of an employment spell are not directly observed (reported) and have to be imputed using earnings information. The main objective of this paper is to investigate the use of earnings spells in LEED as a measure of job tenure.

Statistics NZ and previous studies have defined a job in LEED as a contiguous set of months with non-zero earnings between an employer and employee that lasts at least one month. This means that an employment relationship that contains two or more earnings spells is interpreted in LEED as two or more separate job spells. This paper will attempt to answer two specific questions. First, to what extent do employment relationships in LEED contain multiple job (earnings) spells. And second, what is the impact on the tenure distribution if individual job spells, between an employer and employee, are joined together.

There is some evidence that LEED may overestimate the number of 'short' duration jobs in the New Zealand economy. Statistics New Zealand report that 41.8 percent of jobs in LEED, at 31 March 2006, have been going for 12 months or less. When compared with other developed countries, New Zealand appears to have nearly twice as many jobs lasting less than one year. In the US, 24.4 percent of workers report being with their current employer for less than 12 months, compared with 20.1 percent in Australia (employed for 12 months or less) ${ }^{2}$. The hypothesis is that LEED overestimates the number of short jobs when tenure is measured using individual job spells. Survey-based measures of job tenure (used in the US and Australia) are based on a respondent deciding when they began their current job. The assumption is that a survey-based measure of job tenure is likely to better capture the true length of a job because an individual will link together multiple earnings spells if they represent a continuous employment relationship. 


\section{Data $^{3}$}

LEED contains data on individuals' wage and salary earnings, self-employment earnings, income from Accident Compensation Corporation (ACC) earningsrelated compensation, income from working-age benefits, and income from New Zealand Superannuation. Employment activity can be inferred on the basis of whether employee or self-employment income was received.

At the time this study was begun, the period covered by LEED was eight years, from 1 April 1999 to 31 March 2007. We have used all the currently available data, excluding self-employment earnings. A limitation of using LEED to measure job tenure is that the maximum tenure observable will be equal to eight years, the number of years available in LEED for this study. The narrow study window in LEED also means that some jobs will have started before the first month in LEED and/or are still going on the last month in LEED. We will return to the issue of left and right censoring of job spells and how this impacts on measuring job tenure.

In this study we start by measuring job tenure using a method that is approximate to that used by Statistics New Zealand in the publication Employment, Earnings and Income from LEED: 2006 (Statistics New Zealand, 2007). Statistics NZ defines a job spell in LEED as consisting of a set of contiguous months with non-zero earnings between a particular employer and employee. Statistics NZ imputes some one-month periods of nonemployment as periods of employment. This was done when one month of non-employment occurred in between two periods of six successive months with the same employer. To calculate job tenure Statistics NZ selected all wage and salary jobs that were ongoing on 31 March 2006, which excludes all jobs that ended during March 2006. In this study we selected all jobs that received any earnings during March 2006, which includes all jobs that ended in March 2006. We define a job spell in the same way as Statistics NZ, but do not impute any periods of non-employment. Personal and firm characteristics are attached at the middle month of each job spell and employees aged less than 15 years are excluded.

For each job spell we also identify the first month that the employee received earnings from the employer. The distance between the first month of earnings observed in LEED, between an employer and employee, and the reference month (March 2006) is henceforth referred to as the employment relationship. Unlike job spells, employment relationships can contain non-employment periods, that is, at least one month with zero earnings. There were a total of $1,920,290$ jobs that received positive earnings during March 2006. The average length of a job spell was 25.1 months, or just over two years, and job spells were part of an employment relationship that was, on average, around seven months longer (31.9 months).

\section{Employment relationships}

It is possible that definition of a job in LEED, as used by Statistics NZ and others, is not flexible enough to capture all types of employer-employee relationships within LEED. A single continuous employment relationship could become divided into several job spells if it contains one or more months of zero earnings (non-employment). The division of existing employment relationships into several individual jobs spells could bias the job tenure distribution towards shorter jobs and may explain the relatively high proportion of short jobs in the LEED, compared with tenure distributions from cross-section surveys used in other countries (eg Australia, US).

There are several plausible reasons why an employment relationship may be ongoing but includes a nonemployment period or periods. For example, a worker may not get paid in every month or at intervals greater than one month, take a period of unpaid leave, receive other payments in lieu of wages while they recover from an injury (eg ACC payments), or have an agreement with their employer where they do not work in every month (eg to look after their children during school holidays). In other words, within LEED there may be many different types of employment relationships that are only partially recognised (truncated) by defining jobs in terms of a set of contiguous months of non-zero earnings.

\section{Repeat job spells}

A repeat-job spell is part of a relationship between an employer and employee that contain two or more job spells, whereas a single-job spell has only one earnings spell Table 1 presents selected statistics and characteristics for single and repeat-job spells. The first column contains statistics for single-job spells and repeat-job spells are summarised in columns 2-5. Column 2 contains statistics for all repeat-job spells, columns 3-5 divide repeat-job spells by the number of job spells in the employment relationship. 60.1 percent of repeat-job spells are part of an employment relationship with only two jobs spells (column 3), 18.0 percent are part of an employment relationship with three jobs spells (column 4) and 21.3 percent have four or more job spells in their employment relationship (column 5).

Table 1 suggests that repeat spells are relatively short. compared with single-job spells, but repeat-job spells are part of relatively long employment relationships; on average four years. Unsurprisingly, repeat-job spells are common within the agriculture, forestry and fisheries industries, which are associated with seasonal and temporary employment patterns, and among workers aged 65 years and over, who may be using temporary jobs to periodically supplement their retirement savings. Among these groups, repeat job spells are more likely to be part of employment relationships with four or more job spells. An interesting finding from Table 1, which we will return to later, is that the education industry has the 
same share of repeat-job spells as the agriculture, forestry and fisheries industry. You do not necessarily associate the education industry with seasonal or temporary employment patterns. However, it is possible that some workers in the education industry are only employed or receive earnings during the academic year, which typically starts in February and ends in December. This hypothesis is further supported by the fact that nearly three-quarters (71.0 percent) of repeat-job spells in the education sector are separated from the previous spell by one month.

Repeat-job spells are shorter compared with single-job spells, partly because a greater proportion start in February and March compared with single-job spells, therefore, many repeat-job spells have only been going for one or two months. Workers that return to previous employers are associated with seasonal industries (eg agriculture, forestry and fishing), however, around half are only separated by one month of non-employment from a previous spell and one-fifth may be due to holiday breaks during January, especially within the education industry. This could be due to not working during January (eg unpaid leave or they are only contracted for 11 months out of 12) or they may be working, but changes to the dates employees are paid over the Christmas and New Year holidays may mean they receive no pay during January. Therefore, these employees are inferred as not working in LEED.

\section{Comparing the job tenure and employment relationship tenure distributions}

The fact that a majority of repeat spells are only separated from a previous spell by a single month suggests that measuring tenure using job spells may over-estimate the number of employment relationships that genuinely last only a few months. In this section we will test the effect of imputing periods of nonemployment between job spells. We specify an employment relationship from the first month of employment (non-zero earnings) observed in LEED between an employer and employee to the reference month of March 2006. In other words, we impute all inter-job spell periods of non-employment as employment. A job spell, defined above, can be thought of as the exact opposite in that it does not contain any imputation of non-employment periods.

Figure 1 compares the tenure distribution for job spells (solid line) and employment relationships (dashed line). The vertical axis measures the share of all spells in each tenure band. The horizontal axis groups job spells into one month tenure bands. The employment relationship tenure distribution is skewed more to the right (compared with the job tenure distribution) with fewer spells with tenure of 1-12 months and an increase in the share of spells with tenure over 24 months. In particular, there is a relatively large decline, of about one-third, in the share of spells with tenure 1-2 months from 19.8 percent to 12.8 percent and the proportion of spells with tenure of
73-84 months increases by 50.0 percent from 12.0 percent to 18.0 percent. There is a visual shift in the tenure distribution between job spells and employment relationships. However, the employment relationship tenure distribution is still weighted towards jobs that have been going for a few months, even when all interspell non-employment periods are imputed as employment. Just under 40 percent (38.0 percent) of employment relationships have been going for only 12 months or less, compared with half ( 48.1 percent) of job spells. This still appears high compared with job tenure distributions from overseas cross-section surveys, where around a quarter of jobs have elapsed tenure of 12 months or less.

\section{Summary}

The main objective of this paper is to investigate the use of earnings spells in LEED as a measure of job tenure. The paper was motivated by whether LEED could be used to identify and describe seasonal employment patterns, which typically only last for a few months. A concern with using a LEED-based measure of job tenure is that employment relationships that contain several earnings spells will be observed in LEED as a series of short job spells. A comparison of LEED-based measures of job tenure with other countries suggested that New Zealand appears to have twice as many 'Short' jobs that have been going for 12 months or less compared with the US and Australia. The paper addressed two questions. First, to what extent do employment relationships in LEED contain multiple job (earnings) spells. And second, what is the impact on the tenure distribution if individual job spells, between an employer and employee, are joined together.

The study found that one in five jobs (21.1 percent) in LEED, as at March 2006, were repeat spells with the same employer. In other words, the relationship between the employer and employee consisted of more than one earnings spell. An average repeat job spell had been going for just over a year (15.5 months), but was part of an employment relationship with an elapsed tenure of nearly five years (47.7 months). Nearly half (44.4 percent) of repeat-job spells started following a single month of non-employment and only 16.2 percent of repeat spells occurred after a non-employment period of over 12 months.

However, when all non-employment periods, between individual job spells with the same employer, were imputed as employment the effect on the job tenure distribution is measurable, but not particularly dramatic (see Figure 1). For example, the share of job spells with elapsed tenure of 12 months or less falls by only 10 percentage points from 48.1 percent to 38.0 percent, a decline of around 20 percent. It is likely that individual job spells that are separated by a non-employment period of a few years are in fact two individual jobs and not a single employment relationship. Not surprisingly, the 
effect on the tenure distribution reduces when the length of a non-employment period that is imputed is shortened. For example, if non-employment periods of one year or less are imputed, the share of job spells with elapsed tenure of 12 months or less falls by 8 percentage points from 48.1 percent to 40.1 percent, a decline of around 16 percent. Half of this decline is caused by imputing one month non-employment periods.

A distinctive pattern among repeat-job spells is for an earnings spell to end in December and for a new spell to begin in February. Around a quarter of all repeat spells start in February following a one month break in January. In particular, 63.1 percent of job spells in the education industry fall into this category. This pattern may be caused by contracting arrangements or payroll processes over the Christmas and New Year holidays.

It is likely that LEED-based measures of job tenure that define job spells as a contiguous set of months with nonzero earnings will bias downwards mean job tenure and raise the share of jobs that have only been going for a few months. There is some evidence that many repeat job spells are in fact continuing relationships between an employer and employee and not the beginning of a new job. For example, the fact that a half of repeat-job spells are separated from the previous spell by a single month and that many of these single month non-employment periods occur during January (a traditional month for summer holidays in New Zealand).

An additional finding is that LEED-based measures of job tenure may be sensitive to the reference month chosen. Around 45 percent of jobs in March 2006 started during February, March and April with most repeat spells beginning in February and March. Even if many of these jobs continue for more than one or two months, the effect on the elapsed job tenure distribution is to increase the share of 'short' jobs.

LEED-based job tenure statistics produced by Statistics $\mathrm{NZ}$ include the imputing of one month non-employment periods that occur between two job spells of at least six months. Approximately half of repeat-job spells (10 percent of all job spells) that started following a single month of non-employment would have been imputed by Statistics NZ. More importantly, the imputation conducted by Statistics NZ would have had no effect on job spells that had been going for less than six months, in particular, the many two-month job spells in the education industry that started in February following a one-month earnings break. Statistics NZ do not impute non-employment periods when producing LEED-based measures of job turnover. It is possible that the existence of holiday breaks may bias upwards LEED-based measures of job turnover for the March quarter. Overall the imputation of non-employment periods did not have a large effect on the tenure distribution. However, it is possible that the magnitude of the effect on the tenure distribution from imputing non-employment periods may vary across sub-groups (eg where the share of repeat-job spells is relatively large).

Further work should be conducted to better understand whether non-employment periods should be imputed. LEED could be used to identify what workers are doing in-between jobs with the same employer. LEED contains information on income-testing benefits, ACC and NZ Superannuation payments, as well as earnings from other employers. This information could be used to provide a richer picture of multiple-job spell employment relationships and help to identify continuing employment relationships as opposed to relationships that have come to an end.

Figure 1: Job tenure distribution with employment relationship tenure distribution compared with all interspell non-employment periods imputed as employment ${ }^{5}$

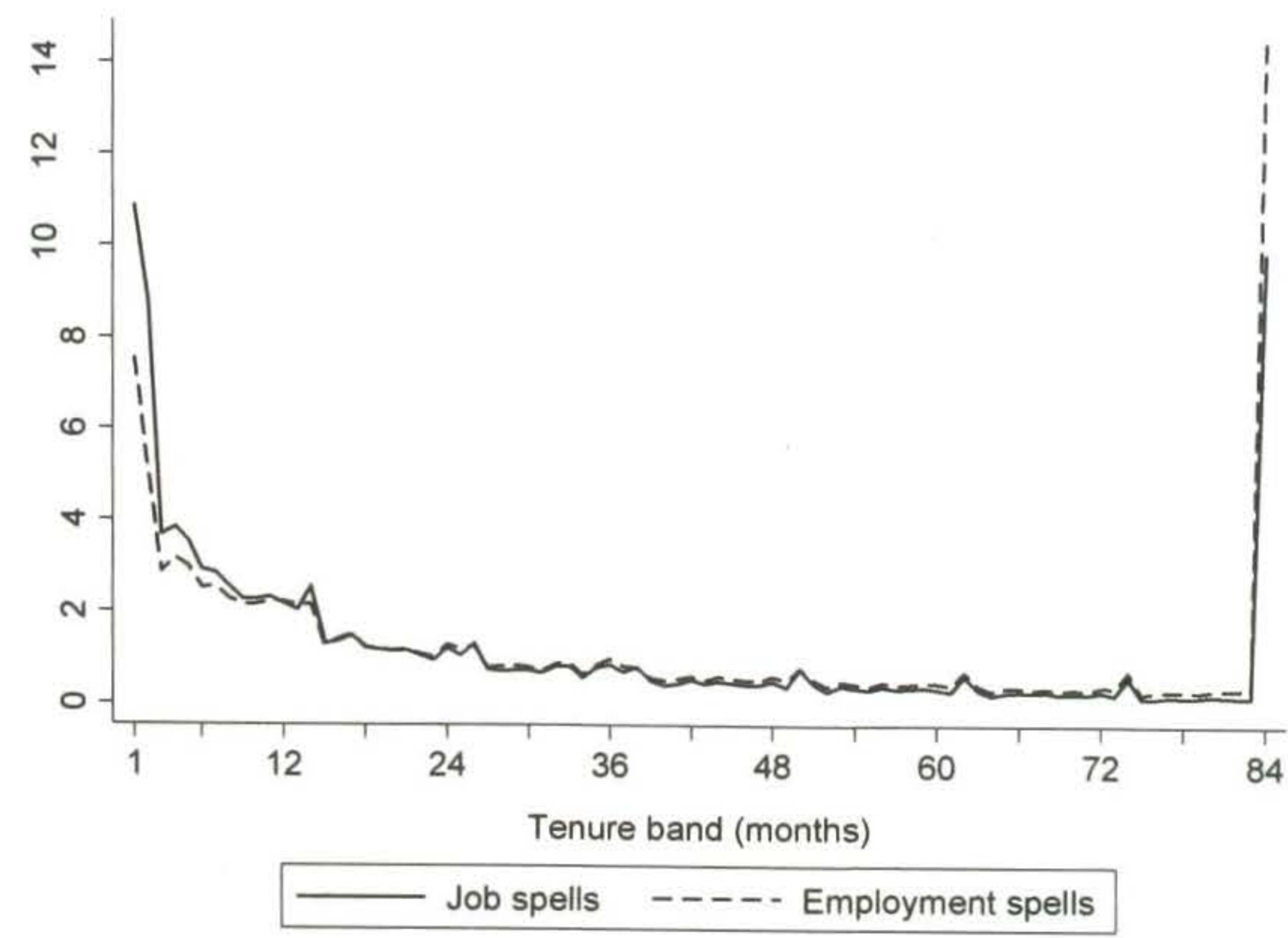


Table 1: Selected employer and employee characteristics for single and repeat job spells ${ }^{4}$

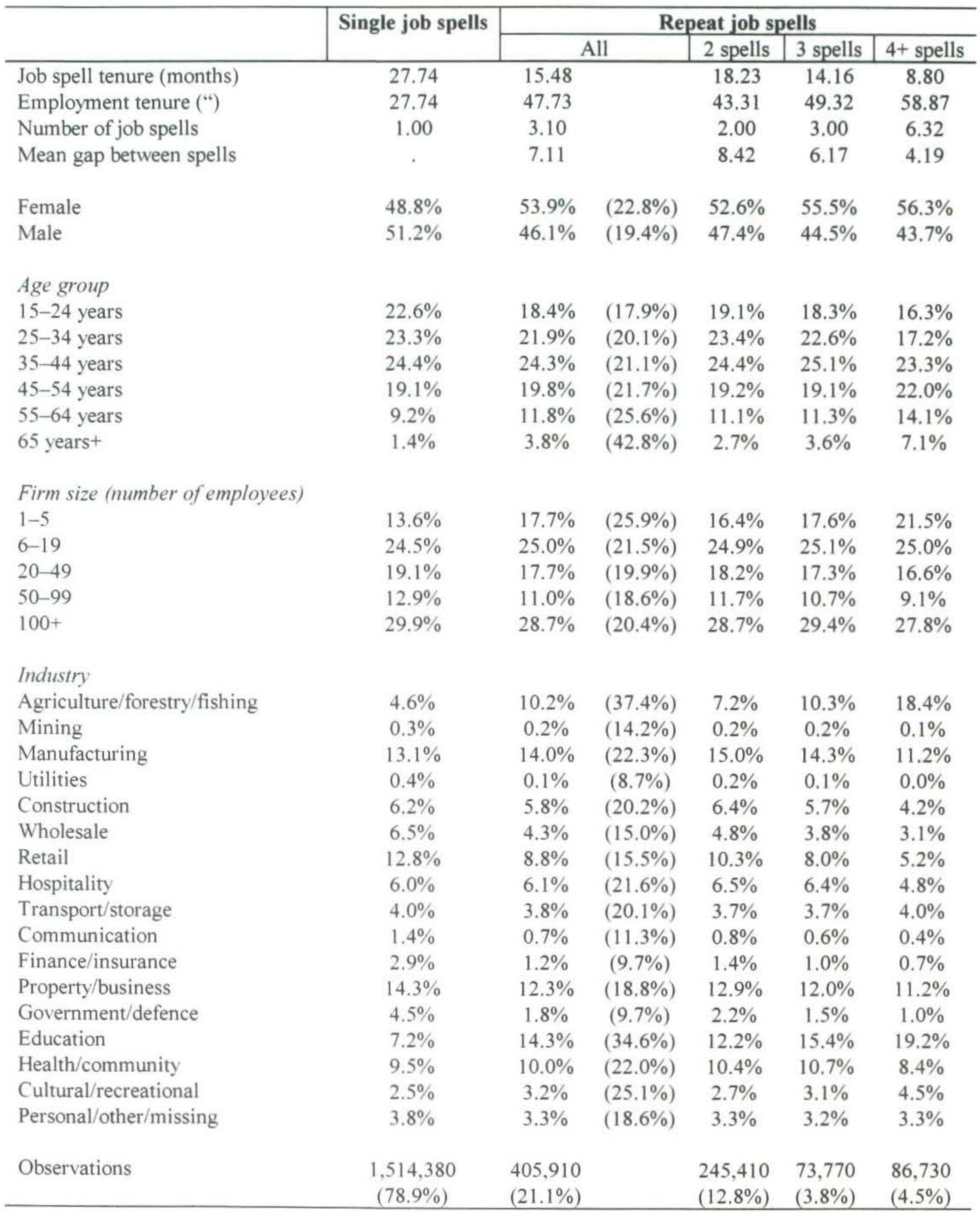

\section{Notes}

1. Please send correspondence to Jason.Timmins@dol.govt.nz.

2. The US job tenure information was obtained from the (annual) supplement to the January 2006 Current Population Survey (CPS). The Australia job tenure information was obtained from the February 2006 Labour Mobility Survey, which is a supplement to the Australian Bureau of Statistics (ABS) monthly Labour Force Survey (LFS).

3. See Timmins (2008) for a detailed description of LEED, the construction of job spells and the selection of the study population.

4. The sample of jobs includes all spells that received any earnings during March 2006 and excludes employees aged less than 15 years (at the middle month of the spell). The first column contains statistics for single-job spells and repeat- 
job spells are summarised in columns 2-5. Column 2 contains statistics for all repeat-job spells, columns 3-5 divide repeat-job spells by the number of job spells in the employment relationship. 60.1 percent of repeat-job spells are part of an employment relationship with only two jobs spells (column 3), 18.0 percent are part of an employment relationship with three jobs spells (column 4) and 21.3 percent have four or more job spells in their employment relationship (column 5).

5. The tenure distributions include all job spells (solid line) and employment (relationships) spells (dashed line) with greater than zero earnings in March 2006. The horizontal axis groups job tenure into single month bands from 1-84 months. The tenure band 84 months groups job and employment spells with tenure of 84 months and over.

\section{References}

Bono, E. del. \& Weber, A. (2008). Do wages compensate for anticipated working time restrictions? Evidence from seasonal employment in Austria. Journal of Labour Economics, 26:1, 181-221.

Raaf, S. de., Kapsalis, C. \& Vincent, C. (2003). Seasonal work and employment insurance use. Perspective on Labour and Income, 4:9, 5-11.

Statistics New Zealand (2007). Employment, Earnings and Income Statistics from LEED: 2006. Statistics New Zealand, Wellington.

Timmins, J. (2008). Why are there so many short jobs in LEED? An analysis of job tenure using LEED. Statistics New Zealand, Wellington.

\author{
Author \\ Jason Timmins \\ Senior Researcher \\ Work Directions \\ Department of Labour \\ P.O. Box 3705 \\ Wellington \\ Jason.Timmins@dol.govt.nz
}

